\title{
Study on ecological compensation for Shaying River Provincial Water function zone
}

\author{
Luo Huihuang ${ }^{1, a}$, Zhao Shanshan ${ }^{2, b}$ and Peng Wenqi ${ }^{3, c}$ \\ ${ }^{1}$ China Institute of Water Resources and Hydropower, Beijing, China \\ ${ }^{2}$ Hebei Agricultural University, Baoding, China \\ ${ }^{3}$ China Institute of Water Resources and Hydropower, Beijing, China

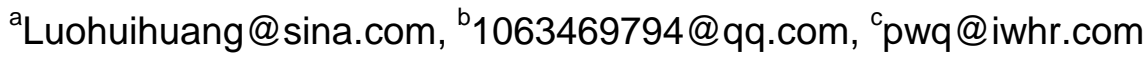

\begin{abstract}
Keywords: provincial, water function zone, water ecological compensation, Shaying River.
Abstract. It is important for provincial water function zone to maintain good water quality for downstream province. In recent years, provincial water function zone water pollution became serious, which caused pollution disputes between upstream province and downstream province. The study on water ecological compensation for water function zone upstream protection is important. The paper study on Shaying River Basin, research on the impact of water quality upstream for excessive emissions on downstream and water pollution loss in provincial water function zone, propose the amount of compensation of provincial water function zone.
\end{abstract}

\section{Introduction}

The provincial water function zone is important for coordinating interprovincial upstream and downstream water function zone water use and water quality. However, the water environment quality in provincial water function zone is not optimistic. The water quality section ratio of I $\sim$ III and IV to grade V and worse than grade V respectively is $62.3 \%, 18.2 \%$ and $19.5 \%$ in 512 important provincial sections. The water quality of provincial cross section is poor in Yellow River base and Huaihe river base; the water quality of provincial cross section is very bad in Haihe River base and Liaohe river base [1]. The downstream water use function is affected, and also cause the water pollution dispute if the water quality in provincial water function zone became deteriorated.

Many scholars have studied the mechanism of water ecological compensation in the interprovincial river basin. Jian $\mathrm{Xu}$ [2] expanded the definition of cross regional water ecological compensation, clearly pointed out that inter regional water ecological compensation from two different administrative areas, and the problems encountered in the implementation process. Yingqiu Liu [3] analyzed Beijing and Tianjin city and Hebei Province Economic and s established the water ecological compensation mechanism. Yicheng Fu [4] discussed the calculation method of water ecological compensation standard of cross regional river basin, given the basis for the calculation of water quantity, water quality and pollutant treatment level, provided the basis for the implementation of ecological compensation mechanism in Yongding river. Xiaohong Liu et al[5] studied the pollution cost data, calculated the compensation standard in the Qian Tang River.

\section{Study area}

The Shaying River in Henan Province, originated from Funiu Mountain, is the largest tributary of Huaihe River in Zhoukou. the upstream is Shahe river in Zhoukou, here in after referred to as the Ying river. Shaying river cross in Henan Province and Anhui Province, flows through the Pingdingshan, Luohe, Zhoukou, Fuyang, ect, the total cities and counties is 40 . The river flows into the Huaihe River at Yingshang County, Anhui Province. The river length is $620 \mathrm{~km}$, which 410km in Henan Province and $210 \mathrm{~km}$ in Anhui Province. Shaying River basin total area is $36651 \mathrm{~km}^{2}, 32539 \mathrm{~km}^{2}$ in Henan Province, $4112 \mathrm{~km}^{2}$ in Anhui Province. The Shaying River is the mainly pollution influence on the main stream of the Huaihe River. The Shaying River basin water pollution is serious and water quality are worse than III. 


\section{Interprovincial Water Function zone ecological compensation}

\section{The amount of pollution loss for provincial water function zone}

We can use Jinxiu Li model [6] to analysis the economic loss caused by water pollution in Shaying River basin. The Li Jinxiu model is as Eq.1:

$$
\gamma_{\mathrm{i}}=\mathrm{K}_{\mathrm{i}}\left[\frac{\mathrm{e}^{0.54(\mathrm{Q}-4)}-1}{\mathrm{e}^{0.54(\mathrm{Q}-4)}+1}+0.5\right]
$$

In Chinese "surface water environment quality standard (GB 3838-2002)", the water environment quality level classify for I, II, III, IV, V and worse than V. In this study, we will categories water quality as value from 1 to 6 , such as the class I corresponds to 1 , II corresponding to 2, III corresponding to 3 and IV corresponding to 4, V corresponding to 5, worse than V corresponding to 6.

According to the water quality monitoring data, and the "surface water environment quality standard (GB 3838-2002)", we can determine the water quality of main functional areas zone in Sha Ying River. We obtain the monthly water quality type of water functional zone, and calculate annual water quality type by weighted average the monthly water quality type. At last, calculate the economic loss caused by water pollution industry by Jinxiu Li model which adopted the annual water quality type.

As we known, agricultural water mainly use from April to August. As a result, the amount of agricultural economic losses by water pollution should be accounted only for the comprehensive water quality type from April to August.

In the paper, we analyze the water pollution economic loss and water ecological compensation for Shaying River provincial water function zone in 2012.

As a result, the total economic loss by water pollution of Zhoukou city in Shaying River was 5.81 billion Yuan, which is 3.5\% of the total GDP in Zhoukou city in Shaying River base, and is $0.4 \%$ of the total GDP in the whole Zhoukou City. The total economic loss by water pollution of Fuyang city in Shaying River was 16.46 billion Yuan, which is $7 \%$ of the total GDP in Fuyang city in Shaying River base, and is $1.9 \%$ of the total GDP in the whole Fuyang City.

\section{The pollution contribution of provincial water function zone}

The pollution transport relationship between upstream and downstream in Shaying River water pollution has is typical. Zhoukou City, which in Henan Province is located in the upper reaches, and Fuyang City, which in Province is located in downstream. The water quality Fuyang City will become worse if there are excessive pollutants in Zhoukou City.

The Sha Ying River is a shallow and narrow river. Then, a one-dimensional water quality model can be used in Shaying River for calculate the provincial water pollution contribution. The model equations are as Eq.2:

$$
\mathrm{C}=\mathrm{C}_{0} \exp \left(-\mathrm{k} \frac{\mathrm{x}}{\mathrm{u}}\right)
$$

In the equation, $\mathrm{C}_{0}$ is for inflow concentration from upstream $(\mathrm{mg} / \mathrm{L}) ; \mathrm{u}$ is for the flow rate $(\mathrm{m} / \mathrm{s}) ; \mathrm{k}$ is for the pollutant comprehensive attenuation coefficient $(1 / \mathrm{d})$; $\mathrm{x}$ is for the distance from the pollution outlet of to the downstream control section $(\mathrm{m})$.

These are many domestic scholars have carried out the research in similar rivers for the pollutant comprehensive attenuation coefficient. Xiaomei Kou [7] find that there are more than $70 \%$ of the river its $\mathrm{k}_{\mathrm{COD}}$ value is $0.20 \sim 0.25 \mathrm{~d}^{-1}$ in the upper reaches of the Han River by the experimental study. Yan Chen et al [8] estimated the COD comprehensive attenuation coefficient of the multi gate dam in the Huaihe River Basin, the COD comprehensive attenuation coefficient of some rivers in the Huaihe River Basin of Henan province was raised from 0.21 to $0.30 \mathrm{~d}^{-1}$. In this paper, the COD comprehensive attenuation coefficient $\mathrm{k}$ in Sha Ying River Basin is $0.25 \mathrm{~d}^{-1}$.

If we consider the point pollution source, the distance of the sewage outlet to the control section of the can is calculated according to the location of the sewage outlet and the location of control section. At the same time, the non-point pollution source is assumed to uniform distributed along the river, 
and we can calculate the distance by assume the pollution source located in middle water function zones position.

\section{The water ecological compensation of water function area zone}

As above, we analyze the water pollution economic loss of each water function zone and the contribution rate of water pollution between the upstream and downstream. Then we can multiple the compensation amount of the pollution loss of and the contribution rate of water pollution, the pollution economic loss for control section of water function area zone is obtained, as shown in Tab 1 and Tab2.

Table 1 Ying Dong-Ying Shang agricultural water function zone economic loss

\begin{tabular}{|c|c|c|c|}
\hline Water function zone & Point pollution & Proportion & $\begin{array}{l}\text { Loss allocation } \\
\text { (Billion Yuan) }\end{array}$ \\
\hline yu-wan buffer zone & & 0.0878 & 0.874 \\
\hline \multirow{9}{*}{$\begin{array}{l}\text { Ying Dong-Ying Shang agricultural water } \\
\text { function zone1 }\end{array}$} & yu min bridge east & 0.0001 & 0.001 \\
\hline & Zhong yuan Rd No.351 & 0.0003 & 0.003 \\
\hline & shang zhuang & 0.0004 & 0.004 \\
\hline & cao zhuang & 0.0003 & 0.003 \\
\hline & da lv village north & 0.0003 & 0.003 \\
\hline & guang wu industrial park & 0.0014 & 0.014 \\
\hline & old bridge & 0.0005 & 0.005 \\
\hline & bus station south & 0.0014 & 0.014 \\
\hline & tai he sewage treatment plant & 0.0031 & 0.031 \\
\hline $\begin{array}{l}\text { Ying Dong-Ying Shang agricultural water } \\
\text { function zone } 2\end{array}$ & & 0.0268 & 0.267 \\
\hline \multirow{2}{*}{ fu yang pollution control zone1 } & fu yang development zones & 0.0002 & 0.002 \\
\hline & Fu yang qilichang & 0.0157 & 0.156 \\
\hline fu yang pollution control zone 2 & & 0.4248 & 4.227 \\
\hline \multirow{2}{*}{$\begin{array}{l}\text { Ying Dong-Ying Shang agricultural water } \\
\text { function zone1 }\end{array}$} & ying shang fertilizer plant & 0.0052 & 0.052 \\
\hline & ying shang xialiuhan & 0.0459 & 0.457 \\
\hline $\begin{array}{l}\text { Ying Dong-Ying Shang agricultural water } \\
\text { function zone } 2 \\
\end{array}$ & & 0.3858 & 3.839 \\
\hline total & & 1.0000 & 9.950 \\
\hline
\end{tabular}

Table 2 Taihe Jieshou-Ying Dong agricultural water function zone economic loss

\begin{tabular}{|l|l|c|c|}
\hline Water function zone & Point pollution & Proportion & $\begin{array}{c}\text { Loss allocation } \\
\text { (Billion Yuan) }\end{array}$ \\
\hline yu-wan buffer zone & & 0.648 & 4.22 \\
\hline \multirow{4}{*}{$\begin{array}{l}\text { Taihe Jieshou-Ying Dong } \\
\text { agricultural water function zone1 }\end{array}$} & yu min bridge east & 0.001 & 0.01 \\
\cline { 2 - 4 } & Zhong yuan Rd No.351 & 0.004 & 0.02 \\
\cline { 2 - 4 } & shang zhuang & 0.004 & 0.03 \\
\cline { 2 - 4 } & cao zhuang & 0.004 & 0.02 \\
\cline { 2 - 4 } & da lv village north & 0.004 & 0.02 \\
\cline { 2 - 4 } & guang wu industrial park & 0.010 & 0.07 \\
\cline { 2 - 4 } & old bridge & 0.003 & 0.02 \\
\cline { 2 - 4 } & bus station south & 0.009 & 0.06 \\
\cline { 2 - 4 } & tai he sewage treatment plant & 0.015 & 0.10 \\
\hline $\begin{array}{l}\text { Taihe Jieshou-Ying Dong } \\
\text { agricultural water function zone2 }\end{array}$ & & 0.299 & 1.94 \\
\hline total & & 1.000 & 6.51 \\
\hline
\end{tabular}

The provincial water ecological compensation of Shaying River water function zones between upstream city and downstream city is $\mathbf{5 0 9 . 4}$ billion Yuan. Zhoukou city which locates in upstream should pay compensation to Fuyang city which locates in downstream, and the total compensation is 509.4 billion Yuan. 


\section{Conclusions}

According to the above research results, Sha Yinghe River in Zhoukou City, the total economic loss was 5.81 billion Yuan, which accounted for Shaying River on a percentage of the total GDP of Zhoukou City of $3.5 \%$, a percentage of the total GDP of Zhoukou City is $0.4 \%$. Shaying River, Fuyang City, the total economic loss for 1.646 billion yuan, which accounted for Sha Sha Yinghe River on a percentage of the total GDP of Fuyang City was $7.0 \%$, a percentage of the total GDP of Fuyang City was $1.9 \%$.

The total compensation for Zhoukou City to Fuyang City is 509.4 billion Yuan. the compensation is the $2.18 \%$ of GDP of Fuyang City in Shaying River Basin, is the 3.08\% of GDP of Zhoukou City in Shaying River Basin.

\section{Acknowledgements}

This study was supported by the IWHR special project (Grant No. 1226), and the National Key Technology R \& D Program (Grant No. 2012BAC06B04).

\section{References}

[1]. National water resources bulletin, 2013, Ministry of Water Resources (In Chinese).

[2]. XU Jian. Legal Coordination Mechanism for the Eco-compensation of Across Boundaries (In Chinese) [J]. LegalForum, 2012, 27(4): 43-50.

[3]. Liu Yingqiu. Study on the ecological compensation mechanism of water in Haihe River Basin (In Chinese) [Z]. Meeting of Experts Committee of China Water Conservancy magazine and to speed up the development of water conservancy reform and development, 2011.

[4]. FU Yi-cheng, RUAN Ben-qing, XU Feng-ran, CHU Li-min. Water related eco-compensation standard study for the Yongding River basin (In Chinese) [J]. SHUILI XUEBAO, 2012, 43(6): 740-748.

[5]. LIU Xiaohong, YU Xijun. A Positive Research on Compensation Mechanism of Water

Eco-System in Qiantang River Basin (In Chinese) [J]. ECOLOGICAL ECONOMY, 2009, (9): 46-50. [6]. LI iin-xiu, SU Song-ling. Calculation model of water pollution induced economic loss for river basin (In Chinese) [J]. SHUILI XUEBAO, 2003, (10): 68-74.

[7]. KOU Xiao-mei. Experimental study on integrated attenuation coefficient of organic contaminant $\left(\mathrm{COD}_{\mathrm{Cr}}\right)$ in upper reaches of Hanjiang River (In Chinese) [J]. WATER RESOURCES

PROTECTION, 2005, 21(5): 31-33.

[8]. Chen Yan, Meng Xilin, Yuan Caifeng, Zhao Yin, Wang Bin. Calculat ing the Fall Coef f icient of COD in Rivers Which Have Many Dams (In Chinese) [J]. Chongqing Environmental Science, 2002, 24(3): 83-85. 